\title{
Ten-Year Trends in the Use of Oral Anticoagulants in Australian General Practice Patients With Atrial Fibrillation
}

Woldesellassie M. Bezabhe ${ }^{1 *}$, Luke R. Bereznicki ${ }^{1}$, Jan Radford ${ }^{1,2}$, Barbara C. Wimmer ${ }^{1}$, Colin Curtain ${ }^{1}$, Mohammed S. Salahudeen ${ }^{1}$ and Gregory M. Peterson ${ }^{1}$

${ }^{1}$ School of Pharmacy and Pharmacology, University of Tasmania, Hobart, TAS, Australia, ${ }^{2}$ Launceston Clinical School, Tasmanian School of Medicine, University of Tasmania, Hobart, TAS, Australia

\section{OPEN ACCESS}

Edited by:

Raymond Noordam,

Leiden University Medical Center, Netherlands

Reviewed by: Bogdan ILEANU, Bucharest Academy of Economic

Studies, Romania

Stella Trompet,

Leiden University Medical Center, Netherlands

*Correspondence: Woldesellassie M. Bezabhe woldesellassie.bezabhe@ utas.edu.au

Specialty section: This article was submitted to Pharmaceutical Medicine and Outcomes Research, a section of the journal Frontiers in Pharmacology

Received: 23 July 2020 Accepted: 18 February 2021 Published: 23 March 2021

Citation:

Bezabhe WM, Bereznicki LR, Radford J, Wimmer BC, Curtain C, Salahudeen MS and Peterson GM (2021) Ten-Year Trends in the Use of Oral Anticoagulants in Australian General Practice Patients With Atrial Fibrillation.

Front. Pharmacol. 12:586370. doi: 10.3389/fphar.2021.586370
Objective: Appropriate use of oral anticoagulants (OACs) reduces the risk of stroke in patients with atrial fibrillation (AF). The study characterized the prescribing of OACs in people with $A F$ in the Australian primary care setting over 10 years.

Design: Retrospective population study.

Setting and Participants: We performed 10 sequential cross-sectional analyses of patients with a recorded diagnosis of AF between 2009 and 2018 using national general practice data. The proportion of patients with AF who were prescribed an OAC based on their stroke risk was examined.

Primary and secondary outcomes: The primary outcome was the proportion of high stroke risk patients who were prescribed an OAC over a decade. The secondary outcome was variation in $\mathrm{OAC}$ prescribing among general practices.

Results: The sample size of patients with AF ranged from 9,874 in 2009 to 41,751 in 2018. The proportion who were prescribed an OAC increased from 39.5\% (95\% Cl 38.6-40.5\%) in 2009 to $52.0 \%$ (95\% Cl 51.5-52.4\%) in 2018 ( $p$ for trend < 0.001$)$. During this time, the proportion of patients with $\mathrm{AF}$ and high stroke risk who were prescribed an OAC rose from $41.7 \%$ (95\% Cl 40.7-42.8\%) to 55.2\% (95\% Cl 54.7-55.8\%; $p$ for trend < 0.001 ) with the direct-acting oral anticoagulants accounting for over three-quarters of usage by 2018. There was substantial variation in OAC prescribing between general practices. In 2018, the proportion of moderate to high stroke risk patients who were prescribed an OAC was $38.6 \%(95 \% \mathrm{Cl} 37.2-40.1 \%)$ in the lowest practice site quintiles and 65.6\% (95\% Cl $64.5-66.7 \%)$ in the highest practice site quintiles.

Conclusions: Over the 10 years, OAC prescribing in high stroke risk patients with AF increased by one-third. There was considerable variation in OAC prescribing between general practices.

Keywords: trends, anticoagulants, atrial fibrillation, general practice, primary care, Australia 


\section{BACKGROUND}

Appropriate utilization of oral anticoagulants reduces stroke risk in patients with atrial fibrillation (Aguilar and Hart, 2005). The vitamin $\mathrm{K}$ antagonist, warfarin, has been the mainstay of anticoagulation in $\mathrm{AF}$ for over 2 decades. It decreases the risk of stroke by almost two-thirds (Aguilar and Hart, 2005). However, it has a narrow therapeutic index and is associated with problematic drug and food interactions that require monitoring and dose adjustments. The direct-acting oral anticoagulants (DOACs) are at least non-inferior to warfarin in efficacy and safety (Connolly et al., 2009; Granger et al., 2011; Patel et al., 2011). In Australia, three DOACs (rivaroxaban, dabigatran, and apixaban) were listed for Commonwealth subsidy under the Pharmaceutical Benefits Scheme (PBS) for non-valvular $\mathrm{AF}$ in 2013; since then their overall use has markedly increased (Drug Utilisation Sub-Committee (DUSC), 2016; Admassie et al., 2017; Alamneh et al., 2017; Pol et al., 2018). In contrast, the prescribing of warfarin has declined (Drug Utilisation Sub-Committee (DUSC), 2016; Admassie et al., 2017; Alamneh et al., 2017; Pol et al., 2018).

Recent studies on the utilization of OAC have highlighted both underuse and overuse in patients with AF in Australia (Admassie et al., 2017; Alamneh et al., 2017; Schaffer et al., 2019). The Tasmanian AF Study observed prescribing practice from 2011 to 2015 , and reported that 55 and $63 \%$ of eligible AF patients with a high stroke risk were prescribed an OAC before and after DOACs were listed on the PBS, respectively (Admassie et al., 2017). This study, however, involved only hospitalized patients, who might have been more co-morbid than those managed in primary care; the results therefore may not have reflected OAC prescribing rates in general practices nationally. The current AF prescribing patterns, in relation to stroke risk, in the Australian primary care setting remain unknown.

The primary objective of this study was to investigate the proportion of Australian primary care patients with $\mathrm{AF}$ prescribed an OAC according to their stroke risk, and temporal trends in prescribing patterns over a 10 year period. The secondary objective was to examine variation in OAC prescribing between general practices.

\section{METHODS}

Data for this study was obtained from NPS MedicineWise's dataset, MedicineInsight. This is the largest and the most representative (in terms of gender, age, socioeconomic status) general practice dataset available to researchers in Australia (Busingye et al., 2019; MedicineInsight, 2020). A total of 429 practices sites contributed data for this study.

MedicineInsight uses a third-party tool that extracts, deidentifies and securely transmits patient data each week to its secure data repository. The extraction tool allows developing a longitudinal database of patients in general practices. The data that MedicineInsight collects from general practices include patient demographics, diagnoses, pathology test results, prescribed medications, and reasons for encounter. However, specific patient identifiers, such as patient name, address, and date of birth, are not included in this dataset (MedicineInsight, 2020).

We performed 10 sequential cross-sectional analyses of data on 1 September every year (census date) from September 01, 2009 to September 01, 2018. Patients with a recorded diagnosis of nonvalvular AF were included in each analysis if 1) they were aged 18 years or older and not deceased on or before the census date, 2 ) they had had three or more recorded general practice visits in the previous two years and at least one of these visits was in the last six months, and 2) they had been registered in the general practice's electronic records at least one year before the census date. We excluded patient who had a recorded OAC prescription before the diagnosis of AF. We defined patients with $\mathrm{AF}$ as being prescribed an OAC (warfarin, dabigatran, rivaroxaban or apixaban) or antiplatelet agent (clopidogrel, ticagrelor, aspirin, ticlopidine, prasugrel, dipyridamole, abciximab, eptifibatide or tirofiban) when they had at least one recorded prescription, dated within 365 days before the census date. The prescriptions recorded in this dataset were only those prescribed by general practitioners (GPs). Aspirin is available without a prescription, but we could only capture prescribed data.

For most of our study period, guidelines recommended using the $\mathrm{CHA}_{2} \mathrm{DS}_{2}$-VASc score (congestive heart failure (1 point), hypertension ( 1 point), age $\geq 75$ years ( 2 points), diabetes mellitus (1 point), stroke/transient ischaemic attack (TIA) (2 points), vascular disease (1 point), age 65-74 years (1 point) and sex female (1 point)) for assessing stroke risk and treatment eligibility in patients with AF (Steffel et al., 2018). Current comorbidities and age at the census date were used to calculate $\mathrm{CHA}_{2} \mathrm{DS}_{2}-\mathrm{VASc}$ score. Current comorbidities were defined as those diagnosed and recorded on or before the census date. Patients with $\mathrm{AF}$ were stratified as low risk when $\mathrm{CHA}_{2} \mathrm{DS}_{2}$-VASc was 0 and male or one and female, moderate risk with $\mathrm{CHA}_{2} \mathrm{DS}_{2}-\mathrm{VASc}=1$ and male, and high risk with $\mathrm{CHA}_{2} \mathrm{DS}_{2}$-VASc $\geq 2$ (Steffel et al., 2018). The proportion of patients who were prescribed an OAC, antiplatelet alone, or neither were calculated with 95\% confidence interval (CI) each year on 1 September from September 01, 2009 through September 01, 2018. Temporal trends were shown using graphs and a Cochran-Armitage test for trend (Lachin, 2011) was used to determine if any observed trends were statistically significant.

Similarly, the proportion of patients with moderate to high stroke risk $\left(\mathrm{CHA}_{2} \mathrm{DS}_{2}-\mathrm{VASc} \geq 1\right.$ and male or $\mathrm{CHA}_{2} \mathrm{DS}_{2}-\mathrm{VASc} \geq$ 2) or low stroke risk $\left(\mathrm{CHA}_{2} \mathrm{DS}_{2}-\mathrm{VASc}=0\right.$ for male or $\mathrm{CHA}_{2} \mathrm{DS}_{2}$ $\mathrm{VASc}=1$ for female) who were prescribed an OAC was calculated each year for each practice site. Potentially appropriate prescribing was defined as prescribing of an OAC to patients with a medium to high stroke risk. Potentially inappropriate prescribing was defined as prescribing an OAC to patients with low stroke risk. All practice sites that contributed data at least for a year were included. Prescribing rates were ranked into quintiles and used as an indicator of general practice sites' prescribing performance. The variation between the highest- and lowestprescribing practice quintiles each year was calculated as a prescribing gap. We calculated linear-weighted kappa coefficients for ordered categories to determine whether 
TABLE 1 | Demographic characteristics of patients with atrial fibrillation, 2009-2018.

\begin{tabular}{|c|c|c|c|c|c|c|c|c|c|c|}
\hline Year & 2009 & 2010 & 2011 & 2012 & 2013 & 2014 & 2015 & 2016 & 2017 & 2018 \\
\hline Sample (n) & 9,874 & 13,723 & 17,807 & 22,510 & 26,777 & 32,285 & 35,641 & 38,804 & 41,338 & 41,751 \\
\hline Age (mean (SD) & $\begin{array}{c}75.1 \\
(11.6)\end{array}$ & $75.3(11.7)$ & $75.3(11.8)$ & 75.7 (11.9) & $75.3(11.9)$ & $75.3(12.0)$ & $75.5(11.9)$ & $75.6(11.8)$ & $75.7(11.8)$ & $76.0(11.6)$ \\
\hline Sex-male (\%) & $\begin{array}{l}5,076 \\
(51.4)\end{array}$ & $\begin{array}{l}7,146 \\
(52.1)\end{array}$ & $\begin{array}{l}9,363 \\
(52.6)\end{array}$ & $\begin{array}{c}11,758 \\
(52.2)\end{array}$ & $\begin{array}{c}14,251 \\
(53.2)\end{array}$ & $\begin{array}{c}17,226 \\
(53.4)\end{array}$ & $\begin{array}{c}19,119 \\
(53.6)\end{array}$ & $\begin{array}{c}20,903 \\
(53.9)\end{array}$ & $\begin{array}{c}22,301 \\
(54.0)\end{array}$ & $\begin{array}{c}22,700 \\
(54.4)\end{array}$ \\
\hline \multicolumn{11}{|l|}{ Indigenous status (\%) } \\
\hline ATSI & $69(0.7)$ & $119(0.9)$ & $178(1.0)$ & $230(1.0)$ & $277(1.0)$ & $343(0.6)$ & $398(1.1)$ & $452(1.2)$ & $509(1.2)$ & $540(1.3)$ \\
\hline Non-ATSI & $\begin{array}{l}6,359 \\
(64.4)\end{array}$ & $\begin{array}{l}9,030 \\
(65.8)\end{array}$ & $\begin{array}{c}12,549 \\
(70.5)\end{array}$ & $\begin{array}{c}16,313 \\
(72.5)\end{array}$ & $\begin{array}{c}20,732 \\
(77.4)\end{array}$ & $\begin{array}{c}25,530 \\
(79.1)\end{array}$ & $\begin{array}{c}28,974 \\
(81.3)\end{array}$ & $\begin{array}{c}32,190 \\
(83.0)\end{array}$ & $\begin{array}{c}34,777 \\
(84.1)\end{array}$ & $\begin{array}{c}35,442 \\
(84.9)\end{array}$ \\
\hline Missing & $\begin{array}{l}3,446 \\
(34.9)\end{array}$ & $\begin{array}{l}4,574 \\
(33.3)\end{array}$ & $\begin{array}{l}5,080 \\
(28.5)\end{array}$ & $\begin{array}{l}5,967 \\
(26.5)\end{array}$ & $\begin{array}{l}5,768 \\
(21.5)\end{array}$ & $\begin{array}{l}6,412 \\
(19.9)\end{array}$ & $\begin{array}{l}6,269 \\
(17.6)\end{array}$ & $6,162(15.9)$ & $6,052(14.6)$ & $\begin{array}{l}5,769 \\
(13.8)\end{array}$ \\
\hline \multicolumn{11}{|l|}{ State (\%) } \\
\hline NSW & $\begin{array}{l}4,031 \\
(40.8)\end{array}$ & $\begin{array}{l}5,523 \\
(40.3)\end{array}$ & $\begin{array}{l}7,564 \\
(42.5)\end{array}$ & $\begin{array}{l}9,472 \\
(42.1)\end{array}$ & $\begin{array}{c}10,944 \\
(40.9)\end{array}$ & $\begin{array}{c}13,201 \\
(40.9)\end{array}$ & $\begin{array}{c}14,267 \\
(40.0)\end{array}$ & $\begin{array}{c}15,328 \\
(39.5)\end{array}$ & $\begin{array}{c}16,245 \\
(39.3)\end{array}$ & $\begin{array}{c}16,497 \\
(39.5)\end{array}$ \\
\hline $\mathrm{VIC}$ & $\begin{array}{l}2,060 \\
(20.9)\end{array}$ & $\begin{array}{l}3,191 \\
(23.3)\end{array}$ & $\begin{array}{l}4,117 \\
(23.1)\end{array}$ & $\begin{array}{l}5,442 \\
(24.2)\end{array}$ & $\begin{array}{l}5,996 \\
(22.4)\end{array}$ & $\begin{array}{l}7,067 \\
(21.9)\end{array}$ & $\begin{array}{l}7,672 \\
(21.5)\end{array}$ & $8,260(21.3)$ & $8,533(20.6)$ & $\begin{array}{l}8,000 \\
(19.2)\end{array}$ \\
\hline QLD & $\begin{array}{l}1,350 \\
(13.7)\end{array}$ & $\begin{array}{l}1,885 \\
(13.7)\end{array}$ & $\begin{array}{l}2,306 \\
(13.0)\end{array}$ & $\begin{array}{l}2,897 \\
(12.9)\end{array}$ & $\begin{array}{l}3,869 \\
(14.5)\end{array}$ & $\begin{array}{l}4,705 \\
(14.6)\end{array}$ & $\begin{array}{l}5,487 \\
(15.4)\end{array}$ & $5,992(15.4)$ & $6,701(16.2)$ & $\begin{array}{l}7,030 \\
(16.8)\end{array}$ \\
\hline WA & $878(8.9)$ & $1,054(7.7)$ & $1,188(6.7)$ & $1,348(6.0)$ & $2,055(7.7)$ & 2,765 (8.6) & $3,163(8.9)$ & $3,659(9.4)$ & $4,002(9.7)$ & $4,102(9.8)$ \\
\hline TAS & $\begin{array}{l}1,208 \\
(12.2)\end{array}$ & $\begin{array}{l}1,511 \\
(11.0)\end{array}$ & $1,729(9.7)$ & $2,156(9.6)$ & $2,311(8.6)$ & $2,727(8.5)$ & $2,937(8.2)$ & $3,064(7.9)$ & $3,209(7.8)$ & $3,454(8.3)$ \\
\hline SA & $230(12.2)$ & $319(2.3)$ & $534(3.0)$ & $774(3.4)$ & $1,054(3.9)$ & $1,183(3.7)$ & 1,294 (3.6) & $1,345(3.5)$ & $1,393(3.4)$ & $1,421(3.4)$ \\
\hline ACT & $42(0.4)$ & $100(0.7)$ & $126(0.7)$ & $147(0.7)$ & $272(1.0)$ & $351(1.1)$ & $493(1.4)$ & $812(2.1)$ & $874(2.1)$ & $884(2.1)$ \\
\hline NT & $75(0.8)$ & $140(1.0)$ & $243(1.4)$ & $274(1.2)$ & $276(1.0)$ & $286(0.9)$ & $328(0.9)$ & $344(0.9)$ & $381(0.9)$ & $363(0.9)$ \\
\hline \multicolumn{11}{|l|}{ Rurality (\%) } \\
\hline Major cities & $\begin{array}{l}5,189 \\
(52.6)\end{array}$ & $\begin{array}{l}7,355 \\
(53.6)\end{array}$ & $\begin{array}{l}9,460 \\
(53.1)\end{array}$ & $\begin{array}{c}12,237 \\
(54.4)\end{array}$ & $\begin{array}{c}15,167 \\
(56.6)\end{array}$ & $\begin{array}{c}18,469 \\
(57.2)\end{array}$ & $\begin{array}{c}20,528 \\
(57.6)\end{array}$ & $\begin{array}{c}22,581 \\
(58.2)\end{array}$ & $\begin{array}{c}24 \\
251(58.7)\end{array}$ & $\begin{array}{c}23,918 \\
(57.3)\end{array}$ \\
\hline Inner regional & $\begin{array}{l}3,178 \\
(32.2)\end{array}$ & $\begin{array}{l}4,156 \\
(30.3)\end{array}$ & $\begin{array}{l}5,599 \\
(31.4)\end{array}$ & $\begin{array}{l}7,027 \\
(31.2)\end{array}$ & $\begin{array}{l}8,014 \\
(29.9)\end{array}$ & $\begin{array}{l}9,669 \\
(30.0)\end{array}$ & $\begin{array}{c}10,583 \\
(29.7)\end{array}$ & $\begin{array}{c}11,414 \\
(29.4)\end{array}$ & $\begin{array}{c}12,002 \\
(29.0)\end{array}$ & $\begin{array}{c}12,686 \\
(30.4)\end{array}$ \\
\hline Outer regional & $\begin{array}{l}1,340 \\
(13.6)\end{array}$ & $\begin{array}{l}1,968 \\
(14.3)\end{array}$ & $\begin{array}{l}2,465 \\
(13.8)\end{array}$ & $\begin{array}{l}2,917 \\
(13.0)\end{array}$ & $\begin{array}{l}3,228 \\
(12.1)\end{array}$ & $\begin{array}{l}3,624 \\
(11.2)\end{array}$ & $\begin{array}{l}3,928 \\
(11.0)\end{array}$ & $4,123(10.6)$ & $4,307(10.4)$ & $\begin{array}{l}4,317 \\
(10.3)\end{array}$ \\
\hline Remote/very remote & $86(0.9)$ & $137(1.0)$ & $171(1.0)$ & $190(0.8)$ & $221(0.8)$ & $340(1.1)$ & $413(1.2)$ & $481(1.2)$ & $585(1.4)$ & $642(1.5)$ \\
\hline Missing & $81(0.8)$ & $107(0.8)$ & $112(0.6)$ & $139(0.6)$ & $147(0.6)$ & $183(0.6)$ & $189(0.5)$ & $205(0.5)$ & $193(0.5)$ & $188(0.5)$ \\
\hline \multicolumn{11}{|l|}{ SEIFA quintiles (\%) } \\
\hline 1 & $\begin{array}{l}2,177 \\
(22.1)\end{array}$ & $\begin{array}{l}3,030 \\
(22.1)\end{array}$ & $\begin{array}{l}3,810 \\
(21.4)\end{array}$ & $\begin{array}{l}4,500 \\
(20.0)\end{array}$ & $\begin{array}{l}5,020 \\
(18.8)\end{array}$ & $\begin{array}{l}5,828 \\
(18.1)\end{array}$ & $\begin{array}{l}6,375 \\
(17.9)\end{array}$ & $6,847(17.7)$ & $7,113(17.2)$ & $\begin{array}{l}7,022 \\
(16.8)\end{array}$ \\
\hline 2 & $\begin{array}{l}1,702 \\
(17.2)\end{array}$ & $\begin{array}{l}2,238 \\
(16.3)\end{array}$ & $\begin{array}{l}3,233 \\
(18.2)\end{array}$ & $\begin{array}{l}4,183 \\
(18.6)\end{array}$ & $\begin{array}{l}5,032 \\
(18.8)\end{array}$ & $\begin{array}{l}6,213 \\
(19.2)\end{array}$ & $\begin{array}{l}7,027 \\
(19.7)\end{array}$ & $7,690(19.8)$ & $8,227(19.9)$ & $\begin{array}{l}8,376 \\
(20.1)\end{array}$ \\
\hline 3 & $\begin{array}{l}2,622 \\
(26.6)\end{array}$ & $\begin{array}{l}3,571 \\
(26.0)\end{array}$ & $\begin{array}{l}4,613 \\
(25.9)\end{array}$ & $\begin{array}{l}5,839 \\
(25.9)\end{array}$ & $\begin{array}{l}6,911 \\
(25.8)\end{array}$ & $\begin{array}{l}8,287 \\
(25.7)\end{array}$ & $\begin{array}{l}8,991 \\
(25.2)\end{array}$ & $9,560(24.6)$ & $\begin{array}{c}10,231 \\
(24.8)\end{array}$ & $\begin{array}{c}10,498 \\
(25.1)\end{array}$ \\
\hline 4 & $\begin{array}{l}1,466 \\
(14.9)\end{array}$ & $\begin{array}{l}2,014 \\
(14.7)\end{array}$ & $\begin{array}{l}2,612 \\
(14.7)\end{array}$ & $\begin{array}{l}3,332 \\
(14.8)\end{array}$ & $\begin{array}{l}4,177 \\
(15.6)\end{array}$ & $\begin{array}{l}5,085 \\
(15.8)\end{array}$ & $\begin{array}{l}5,731 \\
(16.1)\end{array}$ & $6,410(16.5)$ & $7,010(17.0)$ & $\begin{array}{l}7,177 \\
(17.2)\end{array}$ \\
\hline 5 & $\begin{array}{l}1,815 \\
(18.4)\end{array}$ & $\begin{array}{l}2,747 \\
(20.0)\end{array}$ & $\begin{array}{l}3,398 \\
(19.1)\end{array}$ & $\begin{array}{l}4,480 \\
(19.9)\end{array}$ & $\begin{array}{l}5,446 \\
(20.3)\end{array}$ & $\begin{array}{l}6,622 \\
(20.5)\end{array}$ & $\begin{array}{l}7,254 \\
(20.4)\end{array}$ & $8,017(20.7)$ & $8,489(20.5)$ & $\begin{array}{l}8,414 \\
(20.2)\end{array}$ \\
\hline $\begin{array}{l}\text { Missing } \\
\mathrm{CHA}_{2} \mathrm{DS}_{2}-\mathrm{VASc} \\
\text { score }(\%)\end{array}$ & $92(0.9)$ & $123(0.9)$ & $141(0.8)$ & $176(0.8)$ & $191(0.7)$ & $250(0.8)$ & $263(0.7)$ & $280(0.7)$ & $268(0.7)$ & $264(0.6)$ \\
\hline $\begin{array}{l}\text { Low (0 males, } 1 \text { in } \\
\text { females) }\end{array}$ & $548(5.6)$ & $805(5.9)$ & $1,072(6.0)$ & $1,349(6.0)$ & $1,753(6.6)$ & $2,155(6.7)$ & $2,345(6.6)$ & $2,569(6.6)$ & $2,713(6.6)$ & $2,548(6.1)$ \\
\hline Moderate (1 in males) & $619(6.3)$ & $863(6.3)$ & $1,115(6.3)$ & $1,360(6.0)$ & $1,847(6.9)$ & $2,196(6.8)$ & $2,400(6.7)$ & $2,603(6.7)$ & 2,852 (6.9) & $2,918(7.0)$ \\
\hline $\operatorname{High}(\geq 2)$ & $\begin{array}{l}8,707 \\
(88.2)\end{array}$ & $\begin{array}{c}12,055 \\
(87.9)\end{array}$ & $\begin{array}{c}15,620 \\
(87.7)\end{array}$ & $\begin{array}{c}19,801 \\
(88.0)\end{array}$ & $\begin{array}{r}23,177 \\
(86.6)\end{array}$ & $\begin{array}{c}27,934 \\
(86.5)\end{array}$ & $\begin{array}{c}30,896 \\
(86.7)\end{array}$ & $\begin{array}{c}33 \\
632(86.7)\end{array}$ & $\begin{array}{c}35,773 \\
(86.5)\end{array}$ & $\begin{array}{c}36,285 \\
(87.0)\end{array}$ \\
\hline
\end{tabular}

ATSI, Aboriginal and Torres Strait Islander; SD, standard deviation; SEIFA, socioeconomic indexes for areas.

practice performance remained constant over the study period (Vanbelle and Albert, 2009).

Socio-economic indexes for areas (SEIFA) quintile is an index developed by the Australian Bureau of Statistics (ABS) and ranks areas in Australia from 1 (most disadvantaged area) to 5 (most advantaged area) (Australian Bureau of Statistics, 2018). The ABS categorize rurality into five categories using the Accessibility/Remoteness Index of Australia (ARIA) score.
These categories are major cities (ARIA 0-0.20), inner regional (0.21-2.40), outer regional (2.41-5.92), remote (5.93-10.53), and very remote (10.54-15) (Australian Statistical Geography Standard (ASGS), 2017); we collapsed remote and very remote areas into one group. SAS software (SAS version 9.4, SAS Institute Inc., Cary, NC, United States) was used for all data analyses, and a two-sided $p$-value $<0.05$ was considered statistically significant. 


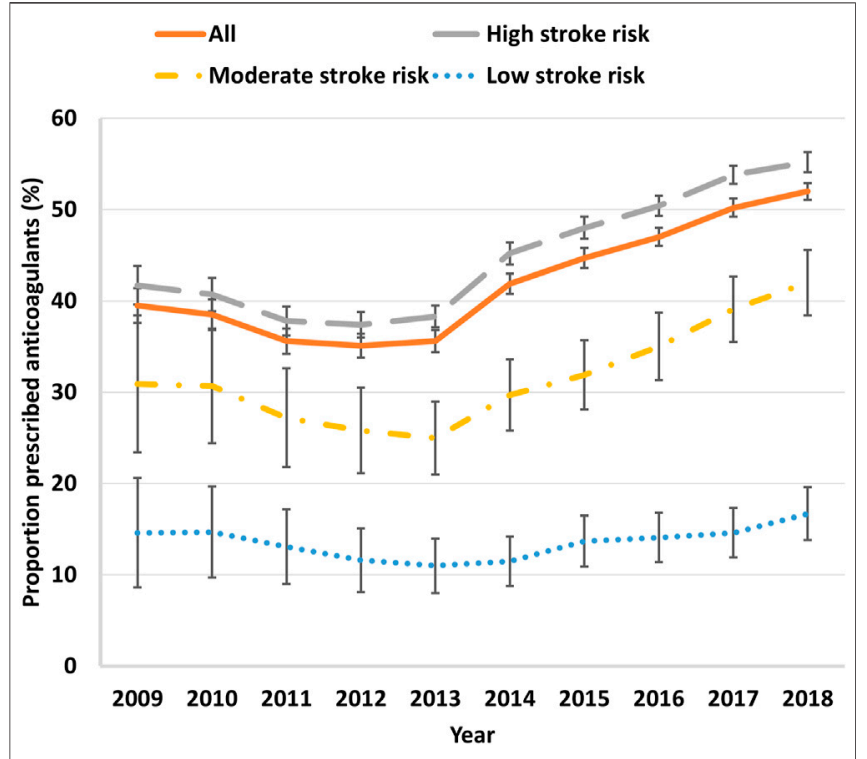

FIGURE 1 | Trends of oral anticoagulant prescribing in Australian general practice patients with atrial fibrillation stratified by CHA2DS2-VASc score, 2009-2018. Error bars indicate 95\% confidence intervals.

Ethics approval was obtained from the Tasmanian Health and Medical Human Research Ethics Committee (H0017648). We also obtained approval to conduct this study from MedicineInsight's independent Data Governance Committee (2018-033). Patients were not identifiable, and individual patient consent was waived for our ethics application.

\section{Patient and Public Involvement}

No patient involved.

\section{RESULTS}

\section{Baseline Characteristics}

The total number of patients with AF included in our consecutive cross-sectional analyses ranged from 9,874 from 169 practice sites in 2009 to 41,751 from 429 practice sites in 2018. The mean age (standard deviation) of patients with AF increased slightly from 75.1 (11.6) years in 2009 to 76.0 (11.6) years in 2018 ( $p$ for trend < 0.001 ). The proportion of male patients increased from $51.4 \%$ (95\% CI $50.4-52.4 \%)$ in 2009 to $54.5 \%$ (95\% CI $54.0-55.0 \%$ ) in 2018 ( $p$ for trend $<0.001$; Table 1).

\section{Oral Anticoagulant Prescribing}

The proportion of patients with $\mathrm{AF}$ and an OAC prescription recorded decreased from $39.5 \%$ (95\% CI 38.6-40.5\%) in 2009 to $35.1 \%$ (95\% CI 34.5-35.8\%) in 2011 and then increased to $52.0 \%$ (95\% CI 51.5-52.4\%) by 2018 ( $p<0.001$; Figure 1). In all patients with $\mathrm{AF}$, lone antiplatelet prescribing dropped steadily from $17.6 \%(95 \%$ CI $16.8-18.3 \%)$ in 2009 to $2.9 \%(95 \%$ CI $2.7-3.0 \%)$ in 2018 ( $p$ for decrease over time <0.001; Supplementary Table S1). However, these latter data are unreliable as patients can obtain aspirin without a prescription. The proportion of people who had no record of a prescription for either treatment to prevent stroke increased from $42.9 \%$ (95\% CI $41.9-43.9 \%$ ) to $51.1 \%$ (95\% CI 50.5-51.7\%) in 2013 and plateaued around $47.0 \%$ between 2014 and 2016, and then declined to $45.2 \%$ (95\% CI $44.7-45.7 \%$ ) in 2018 ( $p$ for increase over time $<0.001$; Supplementary Table S1).

In high-risk patients $\left(\mathrm{CHA}_{2} \mathrm{DS}_{2}-\mathrm{VASc} \geq 2\right)$, the proportion with an OAC prescription recorded increased from $41.7 \%$ (95\% CI 40.7-42.8\%) in 2009 to $55.2 \%$ (95\% CI $54.7-55.8 \%$ ) in $2018(p<0.001)$. In moderate stroke risk patients $\left(\mathrm{CHA}_{2} \mathrm{DS}_{2^{-}}\right.$ $\mathrm{VASc}=1$ and male), the proportion who were receiving an $\mathrm{OAC}$ increased from $30.9 \%$ (95\% CI $27.2-34.7 \%$ ) in 2009 to $42.0 \%$ (95\% CI 40.2-43.8\%) in $2018(p<0.001)$. In low stroke risk patients with $\mathrm{AF}\left(\mathrm{CHA}_{2} \mathrm{DS}_{2}-\mathrm{VASc}=1\right.$ and female, 0 and male), the proportion who were prescribed an OAC decreased from $14.6 \%$ (95\% CI $11.8-17.8 \%$ ) in 2009 to $11.0 \%$ (95\% CI 9.6-12.6\%) in 2013 and then increased to $16.7 \%$ (95\% CI 15.3-18.2\%) in 2018 $(p<0.001$; Figure 1).

\section{General Practices' Prescribing Performance Gap Over Time}

In 2009, the proportion of moderate to high stroke risk patients $\left(\mathrm{CHA}_{2} \mathrm{DS}_{2}-\mathrm{VASc} \geq 1\right.$ and male or $\mathrm{CHA}_{2} \mathrm{DS}_{2}-\mathrm{VASc} \geq 2$ and female) with $\mathrm{AF}$ and an OAC prescription recorded among the lowest prescribing practice quintile was $24.7 \% \quad(95 \%$ CI 22.3-27.4\%), compared with 54.7\% (95\% CI 52.6-56.9\%) in the highest quintile. By 2018, prescribing had increased to $38.6 \%$ (95\% CI 37.2-40.1\%) and 65.6\% (95\% CI 64.5-66.7\%) in the lowest and highest practice quintiles, respectively. The gap between the highest- and lowest-prescribing practice quintiles in OAC prescribing for patients with moderate to high stroke risk

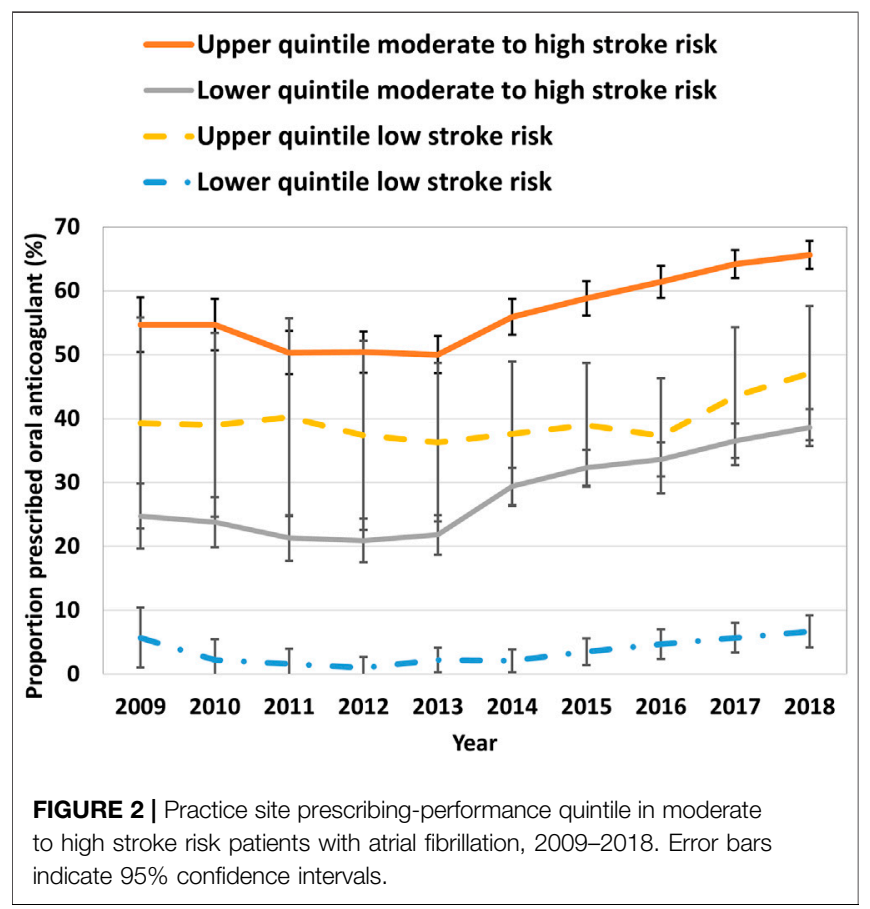




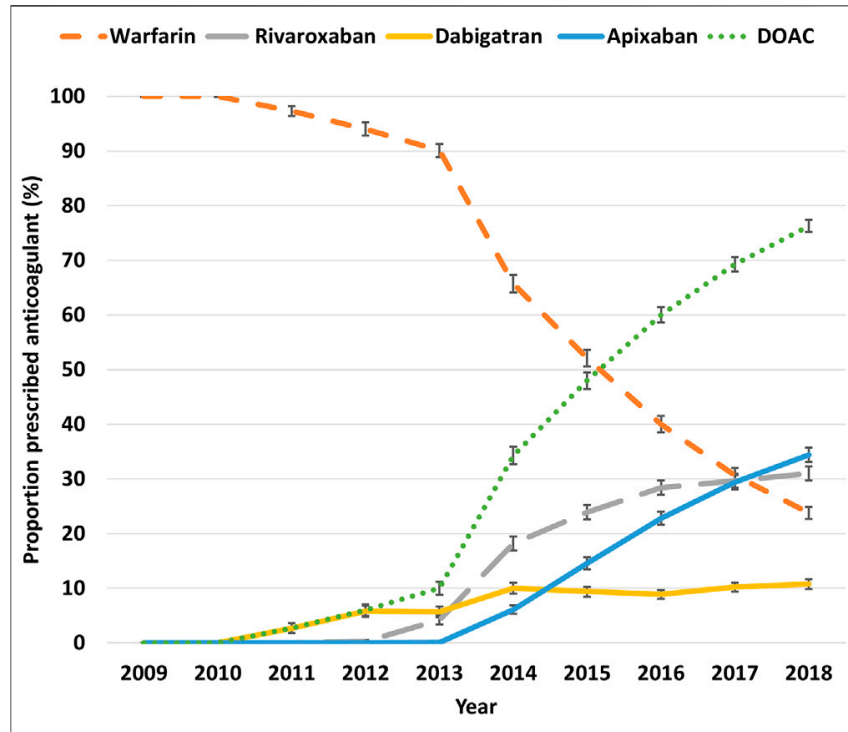

FIGURE 3 | The proportion of patients with atrial fibrillation receiving an oral anticoagulant, 2009-2018. Error bars indicate 95\% confidence intervals.

remained wide, falling slightly from $30.0 \%$ in 2009 to $25.9 \%$ in 2018 (Figure 2).

A total of 429 practice sites contributed data in 2018. Of these, 169 (39.4\%) had provided data since 2009, of which 64 (37.9\%) of practice sites' OAC prescribing quintile did not change, and 120 (71.0\%) practice sites continued in the same or closest prescribing quintile. There was reasonable agreement in practices sites' prescribing quintile between 2009 and 2018, weighted kappa = 0.34 (95\% CI 0.24-0.45) (McHugh, 2012).

In 2009, the proportion of patients with AF who were prescribed an OAC while potentially not recommended $\left(\mathrm{CHA}_{2} \mathrm{DS}_{2}-\mathrm{VASc}=0\right.$ and male or $\mathrm{CHA}_{2} \mathrm{DS}_{2}-\mathrm{VASc}=1$ and female) in the lowest- and highest-prescribing quintiles were $5.7 \%$ (95\% CI 3.7-8.4\%) and 39.3\% (95\% CI 31.3-47.8\%), respectively. At the end of the study period, the proportion of potentially inappropriate prescribing in the lowest- and highest-prescribing quintiles had increased to $6.7 \%$ (95\% CI 5.5-8.0\%) and $47.1 \%$ (95\% CI 41.9-52.4\%), respectively (Figure 2).

\section{Trends in the Use of Warfarin and DOACs}

Among all patients with an OAC prescription recorded, the proportion who were prescribed a DOAC increased rapidly from $2.7 \%$ (95\% CI 2.4-3.3\%) in 2011 to $76.3 \%$ (95\% CI $75.7-76.8 \%$ ) in 2018 , while the proportion of those prescribed warfarin correspondingly decreased from 97.3\% (95\% CI 96.8\% $97.7 \%$ ) to $23.8 \%$ (95\% CI 23.2-24.3\%) (Figure 3; Supplementary Table S2).

\section{DISCUSSION}

The analyses of this large and nationally representative data suggest changing practice trends in the rate and type of OAC prescribing over the 10 year period. The proportion of patients with moderate to high stroke risk who were prescribed an OAC increased steadily by one-third from 2009 to 2018 . This increase in the proportion patients with moderate to high stroke risk who were prescribed an OAC was significantly higher from 2013 onwards, corresponding with the PBS listing of DOACs for Australian government subsidization (rivaroxaban in August 2013, and apixaban and dabigatran in September 2013) (Drug Utilisation Sub-Committee (DUSC), 2016). In 2010, the European Society of Cardiology (ESC) guidelines recommended prescribing of an $\mathrm{OAC}$ for all $\mathrm{AF}$ patients at moderate-high risk of stroke, (i.e., $\mathrm{CHA}_{2} \mathrm{DS}_{2}$-VASc score $\geq 1$ ) instead of antiplatelet therapy (Camm et al., 2010). This was followed by the 2012 ESC's updated recommendation to avoid prescribing of aspirin in low-stroke risk patients (Camm et al., 2012). These changes may also explain the surge in OAC prescribing during the study period (Camm et al., 2012). Similar trends of an increase in OAC use, with a slow initial uptake after the introduction of DOACs, have been reported by studies from the United Kingdom and Denmark (Gadsbøll et al., 2017; Loo et al., 2017).

In 2018, just over half of the high-risk patients were prescribed an OAC. This rate is low compared with the rates reported from previous studies. The Tasmanian AF study found 63\% of highrisk patients were prescribed an OAC. However, that study involved hospitalized patients who might have been more comorbid than general practice patients and it excluded patients with known OAC contraindications. A study in the United Kingdom using general practice data found that over three-quarters of high-risk patients with AF were prescribed an OAC (Adderley et al., 2018). Another study from Denmark found that two-thirds of patients were prescribed an OAC (Gadsbøll et al., 2017).

Despite an overall increase in OAC prescribing over the study period, there remained wide gaps between the highest- and lowest-performing practices in both appropriate (for moderate to high stroke risk) and potentially inappropriate (for low stroke risk) prescribing. One possible reason for the observed gaps in the appropriate use of an $\mathrm{OAC}$ might be the absence of regular reassessment of $\mathrm{CHA}_{2} \mathrm{DS}_{2}$-VASc scores. A study by Yoon et al. (Yoon et al., 2018) found that $46.6 \%$ of low-risk and $72 \%$ of moderate-risk patients at baseline were reclassified as being at high stroke risk within 10 years of follow-up. Increasing GPs' awareness of the need for annual stroke risk assessment may improve OAC prescribing.

\section{STRENGTHS AND LIMITATIONS}

This was the first AF study conducted using MedicineInsight dataset, which provided a large and national study population and thus enabled a comprehensive description of GP prescribing of OACs in Australia (González-Chica et al., 2018; Radford et al., 2018; MedicineInsight, 2020). Furthermore, 10 years sequential cross-sectional analyses enabled characterizing the longitudinal trends in OAC prescribing.

The study has several limitations. The MedicineInsight dataset contains only records of medications prescribed by GPs. 
However, GPs in Australia typically continue those medications prescribed by cardiologists and so the trends described in this study may still be considered accurate and useful with regard to overall OAC prescribing. We did not account for medication contraindications and adverse drug reactions, that may have prevented GPs from prescribing an OAC.

In this study, we used the guidelines retrospectively. For instance, before 2012, OAC treatment was recommended for patients at moderate to high stroke risk, and aspirin was widely used for patients at low stroke risk (Camm et al., 2010). However, the guidelines used for this analysis were in use for most of the study period and are appropriate to evaluate the trends.

\section{CONCLUSION}

Over the 10 years, overall OAC prescribing increased by onethird. By 2018, 55.2\% of the patients with a high stroke risk had an OAC prescription recorded, with the proportion varying substantially between practices. There remains scope to improve $\mathrm{OAC}$ prescribing for $\mathrm{AF}$ in the primary care setting, and the reasons for withholding $\mathrm{OAC}$ therapy in eligible patients need to be investigated.

\section{DATA AVAILABILITY STATEMENT}

The datasets presented in this article are not readily available because the data analyzed in this study was obtained from MedicineInsight with the restriction of not sharing the data publicly. Requests to access these datasets should be directed to MedicineInsight, DataGovernance@nps.org.au. Requests to access the datasets should be directed to DataGovernance@nps.org.au.

\section{REFERENCES}

Adderley, N. J., Ryan, R., Nirantharakumar, K., and Marshall, T. (2018). Prevalence and treatment of atrial fibrillation in UK general practice from 2000 to 2016. Heart 105, 27-33. doi:10.1136/heartjnl-2018-312977

Admassie, E., Chalmers, L., and Bereznicki, L. R. (2017). Changes in oral anticoagulant prescribing for stroke prevention in patients with atrial fibrillation. Am. J. Cardiol. 120 (7), 1133-1138. doi:10.1016/j.amjcard.2017. 06.055

Aguilar, M. I., and Hart, R. (2005). Oral anticoagulants for preventing stroke in patients with non-valvular atrial fibrillation and no previous history of stroke or transient ischemic attacks. Cochrane Database Syst. Rev. (3), CD001927. doi:10. 1002/14651858.CD001927.pub2

Alamneh, E. A., Chalmers, L., and Bereznicki, L. R. (2017). The Tasmanian atrial fibrillation study: transition to direct oral anticoagulants 2011-2015. Cardiovasc. Ther. 35 (3). doi:10.1111/1755-5922.12254

Australian Bureau of Statistics (2018). Socio-economic indexes for areas (SEIFA). Belconnen, Canberra: Australian Bureau of Statistics.

Australian Statistical Geography Standard (ASGS) (2017). Significant urban areas, urban centres and localities, section of state, Belconnen, Canberra: Australian Bureau of Statistics.

Busingye, D., Gianacas, C., Pollack, A., Chidwick, K., Merrifield, A., Norman, S., et al. (2019). Data Resource Profile: MedicineInsight, an Australian national primary health care database. Int. J. Epidemiol. 48 (6), 1741-1741h. doi:10. 1093/ije/dyz147

\section{ETHICS STATEMENT}

The studies involving human participants were reviewed and approved by the Tasmanian Health and Medical Human Research Ethics Committee, University of Tasmania; and the MedicineInsight independent Data Governance Committee. Written informed consent for participation was not required for this study in accordance with the national legislation and the institutional requirements.

\section{AUTHOR CONTRIBUTIONS}

WB participated in the study design, data preparation and manipulation, analysis and interpretation of the data and drafting and revising of the manuscript. GP, LB, JR, and BW participated in the study concept and design. GP, LB, JR, BW, MS, and CC participated in the critical revision of the manuscript.

\section{ACKNOWLEDGMENTS}

We are grateful to the general practices and general practitioners that participate in MedicineInsight, and their patients who allow the use of de-identified information for MedicineInsight.

\section{SUPPLEMENTARY MATERIAL}

The Supplementary Material for this article can be found online at: https://www.frontiersin.org/articles/10.3389/fphar.2021.586370/ full\#supplementary-material.

Camm, A. J., Kirchhof, P., Camm, A. J., Kirchhof, P., Lip, G. Y., Schotten, U., et al. (2010). Guidelines for the management of atrial fibrillation: the task force for the management of atrial fibrillation of the European society of Cardiology. Eur. Heart J. 31 (19), 2369-2429. doi:10.1093/eurheartj/ehq278

Camm, A. J., Lip, G. Y., De Caterina, R., Savelieva, I., Atar, D., Hohnloser, S. H., et al. (2012). 2012 focused update of the ESC Guidelines for the management of atrial fibrillation: an update of the 2010 ESC Guidelines for the management of atrial fibrillation--developed with the special contribution of the European Heart Rhythm Association. Europace 14 (10), 1385-1413. doi:10.1093/ europace/eus305

Connolly, S. J., Ezekowitz, M. D., Yusuf, S., Eikelboom, J., Oldgren, J., Parekh, A., et al. (2009). Dabigatran versus warfarin in patients with atrial fibrillation. $N$. Engl. J. Med. 361 (12), 1139-1151. doi:10.1056/NEJMoa0905561

Drug Utilisation Sub-Committee (DUSC) (2016). Novel oral anticoagulant: predicted vs actual analysis, Public release document. Canberra: Australia Australian Government, Department of Health.

Gadsbøll, K., Staerk, L., Fosbøl, E. L., Sindet-Pedersen, C., Gundlund, A., Lip, G. Y. H., et al. (2017). Increased use of oral anticoagulants in patients with atrial fibrillation: temporal trends from 2005 to 2015 in Denmark. Eur. Heart J. 38 (12), 899-906. doi:10.1093/eurheartj/ehw658

González-Chica, D. A., Vanlint, S., Hoon, E., and Stocks, N. (2018). Epidemiology of arthritis, chronic back pain, gout, osteoporosis, spondyloarthropathies and rheumatoid arthritis among 1.5 million patients in Australian general practice: NPS MedicineWise MedicineInsight dataset. BMC Musculoskelet. Disord. 19 (1), 20. doi:10. 1186/s12891-018-1941-x 
Granger, C. B., Alexander, J. H., McMurray, J. J., Lopes, R. D., Hylek, E. M., Hanna, M., et al. (2011). Apixaban versus warfarin in patients with atrial fibrillation. $N$. Engl. J. Med. 365 (11), 981-992. doi:10.1056/NEJMoa1107039

Lachin, J. M. (2011). Power and sample size evaluation for the Cochran-MantelHaenszel mean score (Wilcoxon rank sum) test and the Cochran-Armitage test for trend. Stat. Med. 30 (25), 3057-3066. doi:10.1002/sim.4330

Loo, S. Y., Dell'Aniello, S., Huiart, L., and Renoux, C. (2017). Trends in the prescription of novel oral anticoagulants in UK primary care. Br. J. Clin. Pharmacol. 83 (9), 2096-2106. doi:10.1111/bcp.13299

McHugh, M. L. (2012). Interrater reliability: the kappa statistic. Biochem. Med. 22 (3), 276-282. doi:10.11613/bm.2012.031

MedicineInsight (2020). in MedicineInsight data book and data dictionary (Sydney, Australia: NPS MedicineWise).

Patel, M. R., Mahaffey, K. W., Garg, J., Pan, G., Singer, D. E., Hacke, W., et al. (2011). Rivaroxaban versus warfarin in nonvalvular atrial fibrillation. N. Engl. J. Med. 365 (10), 883-891. doi:10.1056/NEJMoa1009638

Pol, D., Curtis, C., Ramukumar, S., and Bittinger, L. (2018). NOACs now mainstream for the use of anticoagulation in non-valvular atrial fibrillation in Australia. Heart, Lung Circ. 28, e40-e42. doi:10.1016/j.hlc.2018.03.010

Radford, J., Kitsos, A., Stankovich, J., Castelino, R., Khanam, M., Jose, M., et al. (2018). The epidemiology of chronic kidney disease in Australian general practice: national Prescribing Service MedicineWise MedicineInsight dataset. Nephrology 24, 1017-1025. doi:10.1111/nep.13537

Schaffer, A. L., Falster, M. O., Brieger, D., Jorm, L. R., Wilson, A., Hay, M., et al. (2019). Evidence-practice gaps in postdischarge initiation with oral anticoagulants in patients with atrial fibrillation. J. Am. Heart Assoc. 8 (24), e014287. doi:10.1161/jaha.119.014287

Steffel, J., Verhamme, P., Potpara, T. S., Albaladejo, P., Antz, M., Desteghe, L., et al. (2018). The 2018 European Heart Rhythm Association Practical Guide on the use of non-vitamin $\mathrm{K}$ antagonist oral anticoagulants in patients with atrial fibrillation. Eur. Heart J. 39 (16), 1330-1393. doi:10.1093/eurheartj/ehy136

Vanbelle, S., and Albert, A. (2009). A note on the linearly weighted kappa coefficient for ordinal scales. Stat. Methodol. 6 (2), 157-163. doi:10.1016/j. stamet.2008.06.001

Yoon, M., Yang, P. S., Jang, E., Yu, H. T., Kim, T. H., Uhm, J. S., et al. (2018). Dynamic changes of CHA2DS2-VASc score and the risk of ischaemic stroke in asian patients with atrial fibrillation: a nationwide cohort study. Thromb. Haemost. 118 (7), 1296-1304. doi:10.1055/s-0038-1651482

Conflict of Interest: The authors declare that the research was conducted in the absence of any commercial or financial relationships that could be construed as a potential conflict of interest.

Copyright (c) 2021 Bezabhe, Bereznicki, Radford, Wimmer, Curtain, Salahudeen and Peterson. This is an open-access article distributed under the terms of the Creative Commons Attribution License (CC BY). The use, distribution or reproduction in other forums is permitted, provided the original author(s) and the copyright owner(s) are credited and that the original publication in this journal is cited, in accordance with accepted academic practice. No use, distribution or reproduction is permitted which does not comply with these terms. 